\title{
EDUCAÇÃO DE JOVENS E ADULTOS EM TEMPOS DE PANDE- MIA: ANÁLISE DOS REFLEXOS DO ENSINO REMOTO NO MU- NICÍPIO DO RIO DE JANEIRO
}

\author{
Cirlei Mota Trajano ${ }^{1}$
}

\begin{abstract}
RESUMO
Apesar do grande contingente de jovens e adultos analfabetos no Brasil, as políticas públicas voltadas exclusivamente para a modalidade não conseguem incluir esses sujeitos de forma satisfatória na sociedade. Em tempos de emergência e distanciamento social, o impacto na educação desses indivíduos pode ser desastroso. A partir disso, o objetivo deste artigo é analisar de que forma as ações de Ensino Remoto da prefeitura do Rio de Janeiro refletem na educação de jovens e adultos das escolas públicas do município no período de distanciamento social. Iniciase o texto, fazendo uma breve reflexão sobre as principais políticas públicas que norteiam a modalidade, dando ênfase ao Projeto de Educação de Jovens e Adultos, implementado no município do Rio de Janeiro em 2005 e vigente até os dias atuais. Parte-se depois para uma reflexão acerca do uso das tecnologias da informação e comunicação, discorrendo acima de tudo sobre o Ensino Remoto e seus reflexos na Educação de Jovens e Adultos. Por fim, faz-se uma análise dos efeitos do Ensino Remoto para esse público, a partir das percepções dos professores que lecionam na modalidade. Os resultados obtidos permitem afirmar que o Ensino Remoto contribui para reforçar a exclusão social dos alunos dessa modalidade, uma vez que não leva em conta as especificidades desses sujeitos.
\end{abstract}

Palavras-chave: Educação de Jovens e Adultos. Ensino Remoto. PEJA.

\begin{abstract}
Despite the large number of illiterate young and adults in Brazil, public policies focused exclusively on the modality have been unable to adequately include these people in society (MACHADO, 2017). In times of emergency and social distancing, the impact on the education of these individuals can be disastrous. Based on this statement, this paper aims to analyze how the Remote Education actions in the city of Rio de Janeiro reflect in the education of young and adults in public schools in the city during the period of social distance. The text begins with a brief reflection on the main public policies that guide the modality, with emphasis to the Young and Adult Education Project (PEJA), implemented in the city of Rio de Janeiro in 2005 and current until the present day. Then it reflects on the use of information and communication technologies, discussing above all about Remote Education and its effects on Young and Adult Education. Lastly, it analyzes the effects of Remote Education for this public, starting on the perceptions of teachers who teach in this modality. The results obtained allow to affirm that Remote Education contributes to reinforce the social exclusion of students in this modality, since it does not take into account the specificities of these people.
\end{abstract}

Keywords: Young and Adult Education. Remote Education. PEJA.

RESUMEN

A pesar del gran número de jóvenes y adultos analfabetos en Brasil, las políticas públicas centradas exclusivamente en la modalidad no pueden incluir satisfactoriamente estos temas en la sociedad (MACHADO, 2017). En tiempos de emergencia y distanciamiento social, el impacto en la educación de estas personas puede ser desastroso. Con base en esto, el objetivo de este artículo es analizar cómo las acciones de enseñanza remota de la ciudad de Río de Janeiro se reflejan en la educación de jóvenes y adultos en las escuelas públicas del municipio durante el

\footnotetext{
${ }^{1}$ Doutoranda em Ciências da Educação pela Universidade Lusófona de Humanidades e Tecnologias. Mestre em Língua Portuguesa pela Universidade Federal Rural do Rio de Janeiro (2018). Atualmente é professora titular de língua portuguesa da Prefeitura Municipal de Angra dos Reis e professora titular de língua portuguesa da Prefeitura da Cidade do Rio de Janeiro.
} 


\section{Out.-Nov. 2021 \\ v.1, n.9, 03-24 \\ ISSN: 2676-0428}

período de distanciamiento social. El texto comienza, haciendo una breve reflexión sobre las principales políticas públicas que guían la modalidad, haciendo hincapié en el Proyecto de Educación de Jóvenes y Adultos, implementado en la ciudad de Río de Janeiro en 2005 y vigente hasta el día de hoy. A continuación, se reflexiona sobre el uso de las tecnologías de la información y la comunicación, debatiendo sobre todo sobre la Educación a Distancia y sus reflexiones en la Educación de Jóvenes y Adultos. Finalmente, se realiza un análisis de los efectos de la Educación Remota para este público, a partir de las percepciones de los docentes de la modalidad. Los resultados obtenidos permiten afirmar que la Educación a Distancia contribuye a reforzar la exclusión social del alumnado en esta modalidad, ya que no tiene en cuenta las especificidades de estas asignaturas.

Palabras clave: Educación de Jóvenes y Adultos. Enseñanza a Distancia. PEJA.

\section{INTRODUÇÃO}

Diante a um cenário de incertezas em relação ao retorno às aulas presenciais nas escolas públicas e privadas em todo território nacional, devido às medidas de distanciamento social no controle da pandemia de COVID-192, muitos governantes correram contra o tempo, para implementar mecanismos de aprendizagem remota que permitissem aos alunos continuarem os estudos em suas casas. No entanto, o que se percebe na prática é um grande atropelo da aprendizagem e o desnudamento do abismo social que impera na sociedade.

São vários as hipóteses que reforçam essa tese e convergem para o reforço da exclusão social dos alunos da Educação Jovens e Adultos, como por exemplo: (a) Grande parte dos alunos não têm acesso a recursos, como equipamentos e internet de alta conexão, para acessar conteúdos digitais; (b) A maioria dos alunos não têm autonomia para uma aprendizagem a distância, aumentando ainda mais o abandono escolar; e (c) Os docentes não têm formação adequada para lidar com as tecnologias da informação e comunicação.

No município do Rio de Janeiro, a Secretaria de Educação pois em prática o Ensino Remoto em plataformas e redes sociais, para os alunos acessarem. Não há na literatura muitos estudos a respeito do tema, o que gera muitos equívocos por parte de pais, alunos e até mesmo professores que estão utilizando essa modalidade de ensino. Dessa forma, faz-se necessário pontuar sobre as principais diferenças entre o Ensino Remoto e a Educação a distância e refletir sobre a viabilidade do uso das tecnologias da informação e comunicação na educação como um todo, sobretudo na Educação do Jovens e Adultos, já que é uma modalidade direcionada a um sujeito marcado pela exclusão social.

\footnotetext{
${ }^{2}$ Informações disponíveis em: https://www.paho.org/bra/index.php?option=com content\&view=article\&id=6101: covid19\&ltemid=875, recuperado em 28 de junho, 2019.
} 
A partir disso, pretende-se com este artigo analisar se as ações da prefeitura do Rio de janeiro têm obtido êxito na aplicação do Ensino Remoto no Programa de Educação de Jovens e Adultos. Para isso, serão apresentadas as percepções dos profissionais da área, acerca das ações adotadas pela prefeitura e a viabilidade dessas medidas diante à realidade desses sujeitos.

Do ponto de vista metodológico, a análise foi produzida num contexto de estudo quantitativo e qualitativo, cujo procedimento fundamental foi a análise do dossiê sobre Consulta aos Professores/as das Redes Municipais do Estado do Rio de Janeiro sobre Educação Remota, realizada pelo Fórum de Educação de Jovens e Adultos do estado do Rio de Janeiro - Fórum EJA-RJ, e estudo de caso, com levantamento de informação obtida por meio de entrevistas semiestruturadas, com professores de PEJA, de distintas áreas, de uma escola pública situada na periferia da cidade.

Autores como Freire (2005, 2009), Haddad (1999, 2019), Machado (2016), Motta e Frigotto (2017) e Schwartz (2002) contribuíram de forma significativa para o entendimento político e social da EJA no país. Os estudos de Moran (2002, 2007, 2015) nortearam o conhecimento sobre o Ensino a Distância, que é a base do Ensino Remoto utilizado nesse contexto de emergência social. A pesquisa de Fávero, Andrade e Brenner (2007) em relação ao PEJA complementaram a estrutura teórica do artigo.

A partir da análise das informações recolhidas foi possível constatar que o Ensino Remoto não contempla de forma satisfatória os alunos do PEJA. Apesar dessa modalidade ser aplicada num momento de emergência, não permitindo as autoridades governamentais tempo hábil para viabilizar um ensino mais adequado, faz-se necessário e urgente implementar políticas públicas no dia a dia mais eficientes, que permitam a inclusão desse grupo numa sociedade globalizada e cada vez mais digitalizada.

\section{EDUCAÇÃO DE JOVENS A ADULTOS: BREVE REFLEXÃO E CENÁRIO ATUAL}

A Educação de Jovens e Adultos (EJA) é o resultado de uma luta histórica da educação, para garantir o direito universal de todo cidadão que, por motivos diversos, não puderam concluir o ensino formal na educação obrigatória, dos 4 
aos 17 anos. Antes de abordarmos a legislação vigente sobre a modalidade e refletir sobre o contexto presente, vale destacar que o ensino de jovens e adultos no Brasil foi, e continua sendo, um ato de resistência a uma realidade social, que vai além da simples busca pela escolarização formal. Machado (2016, p. 432) destaca que:

\begin{abstract}
Cabe ressaltar, todavia, que a EJA não se reduz a escolarização. Sua história, na realidade brasileira, e também na realidade latino-americana, abarca a luta pelo direito de acesso, permanência e conclusão da escolarização com qualidade, em consonância com inúmeras outras lutas: pelos direitos à saúde, ao trabalho, à moradia digna (seja no campo ou nas cidades), à igualdade de gênero, ao respeito às diversidades, dentre tantas outras, que a configuram como educação ao longo de toda a vida e pela construção de uma sociedade que, de fato, seja espaço de vivência e convivência de todas e todos (MACHADO, 2016, p. 432).
\end{abstract}

Dentro desse contexto histórico de luta e perseverança para a implementação de uma política pública para EJA, não há como não destacar as contribuições de Paulo Freire na alfabetização de adultos. Sua metodologia de ensino, de essência reflexiva e transformadora, levava em conta a realidade do próprio educando, para criar temas geradores e, a partir disso, sistematizar a escrita e a leitura. Nesse método, a aprendizagem ocorria dialogicamente da interação professor-aluno (FREIRE, 2005, 2009).

As concepções freiriana rompiam com o pensamento pedagógico da época, que copiava os modelos importados, e ia de encontro aos interesses políticos, dominados pela ditadura militar. Paulo Freire chegou a ser preso, não só por alfabetizar adultos, mas principalmente por estimular a compreensão da consciência política e social do trabalhador através da educação (Haddad, 2019). Como afirma Gadotti (2012, p. 10):

\begin{abstract}
A coragem de pôr em prática um autêntico trabalho de educação que identifica a alfabetização com um processo de conscientização, capacitando o oprimido tanto para a aquisição dos instrumentos de leitura e escrita quanto para a sua libertação fez dele um dos primeiros brasileiros a serem exilados. [...] A metodologia por ele desenvolvida foi muito utilizada no Brasil em campanhas de alfabetização e, por isso, ele foi acusado de subverter a ordem instituída, sendo preso após o Golpe Militar de 1964. Depois de 72 dias de reclusão, foi convencido a deixar o país (GADOTTI, 2012, p. 10).
\end{abstract}

Assim como Paulo Freire desafiou o pensamento pedagógico culturalmente dependente das ideologias da elite, para implementar sua concepção de educação popular ativa e crítica, comprometida com o diálogo, atualmente 
muitos trabalhadores pobres, periféricos, desafiam diariamente a realidade do abismo da desigualdade social, para continuar lutando pelo direito de ter acesso à educação pública de qualidade. Apesar de ser garantida pela Constituição Federal de 1988, a EJA somente foi reconhecida como modalidade da Educação Básica em 1996, com a promulgação da Lei de Diretrizes e Bases da Educação Nacional (Lei n. 9.394/96), como pode ser visto abaixo:

\begin{abstract}
Artigo 37. A educação de jovens e adultos será destinada àqueles que não tiveram acesso ou continuidade de estudos no ensino fundamental e médio na idade própria.

Parágrafo $1^{\circ}$ Os sistemas de ensino assegurarão gratuitamente aos jovens e aos adultos, que não puderam efetuar os estudos na idade regular, oportunidades educacionais apropriadas, consideradas as características do alunado, seus interesses, condições de vida e de trabalho, mediante cursos e exames. Parágrafo $2^{\circ} \mathrm{O}$ Poder Público viabilizará e estimulará o acesso e a permanência do trabalhador na escola, mediante ações integradas e complementares entre si.

Artigo 38. Os sistemas de ensino manterão cursos e exames supletivos, que compreenderão a base nacional comum do currículo, habilitando ao prosseguimento de estudos em caráter regular.

Parágrafo $1^{\circ}$ Os exames a que se refere este artigo realizar-se-ão:

I - no nível de conclusão do ensino fundamental, para os maiores de quinze anos:

II -no nível de conclusão do ensino médio, para os maiores de dezoito anos. Parágrafo $2^{\circ}$ Os conhecimentos e habilidades adquiridos pelos educandos por meios informais serão aferidos e reconhecidos mediante exames (BRASIL, 1996).
\end{abstract}

Conforme o texto aprovado, na nova modalidade de ensino, é assegurada aos jovens e adultos a continuidade dos estudos e a inserção no mundo produtivo, nas mesmas condições dos alunos que cursam o Ensino Fundamental e Médio, sem qualquer tipo de discriminação. Nesse sentido, há um reforço da garantia das condições de acesso e permanência na escola, ampliando a concepção para uma educação permanente e qualificação de vida para todos, condição esta inerente ao desenvolvimento da pessoa humana (HADDAD, 2007).

No ano de 2000, foi expedida as Diretrizes Curriculares Nacionais para a EJA (Resolução CNE/CEB n. 1/2000 e Parecer CNE/CEB n. 11/2000). Esses documentos apontam que a modalidade de ensino deve considerar as situações, os perfis dos estudantes, as faixas etárias e se pautará pelos princípios de equidade, diferença e proporcionalidade na apropriação e contextualização das diretrizes curriculares nacionais e na proposição de um modelo pedagógico próprio.

No ano seguinte foi aprovado o Plano Nacional de Educação (PNE), promulgado pela Lei $n^{0} 10.172 / 2001$, que determina diretrizes, metas e estratégias para a política educacional no período de 2001 a 2010. Em 2014, A Lei nํ 13.005

\title{
ILSARSOS AENIIHOOS UTRAPASSANDOFRONIBRASECONIEXTOSTEMÁTOOS
}


aprovou o PNE 2014-2024. Os documentos enfatizam o alinhamento da EJA ao Ensino Profissional e define como um dos objetivos do plano a integração de ações do poder público que conduzam à erradicação do analfabetismo. Das 20 metas propostas pelo documento, quatro delas dizem respeito diretamente ao aluno da EJA:

\begin{abstract}
Meta 3: universalizar, até 2016, o atendimento escolar para toda a população de 15 (quinze) a 17 (dezessete) anos e elevar, até o final do período de vigência deste PNE, a taxa líquida de matrículas no ensino médio para $85 \%$ (oitenta e cinco por cento).

Meta 8: elevar a escolaridade média da população de 18 (dezoito) a 29 (vinte e nove) anos, de modo a alcançar, no mínimo, 12 (doze) anos de estudo no último ano de vigência deste plano, para as populações do campo, da região de menor escolaridade no País e dos $25 \%$ (vinte e cinco por cento) mais pobres, e igualar a escolaridade média entre negros e não negros declarados à Fundação Instituto Brasileiro de Geografia e Estatística - IBGE.

Meta 9: elevar a taxa de alfabetização da população com 15 (quinze) anos ou mais para 93,5\% (noventa e três inteiros e cinco décimos por cento) até 2015 e, até o final da vigência deste PNE, erradicar o analfabetismo absoluto e reduzir em $50 \%$ (cinquenta por cento) a taxa de analfabetismo funcional.

Meta 10: oferecer, no mínimo, 25\% (vinte e cinco por cento) das matrículas de educação de jovens e adultos, nos ensinos fundamental e médio, na forma integrada à educação profissional (PNE, 2014, pp. 22, 33, 35, 37).
\end{abstract}

De forma geral, há de reconhecer os avanços da legislação vigente no tocante ao atendimento aos jovens e adultos em condições de maior vulnerabilidade na sociedade. Dessa forma, é de se esperar que o ensino da EJA consiga cumprir a função de ser reparadora, equalizadora e qualificadora, como apontado pelo Parecer CNE/CEB 11/2000. No entanto, como será possível constatar ao longo do artigo, a realidade em torno desse sujeito se mostra cheia de desafios, muitas vezes difíceis de serem superados.

Nos dias de hoje, é possível perceber uma política pública educacional que exclui ainda mais o jovem trabalhador das salas de aula. Só na última década, Estados e Municípios fecharam cerca de $34 \%$ de escolas que ofereciam a EJA por falta de investimento (INEP, 2018). Essas condições precárias, de acesso e permanência, foram intensificadas com a aprovação da Emenda Constitucional no 95, de 15 de dezembro de 2016 (EC 95/2016), que congela o orçamento público por 20 anos, afetando severamente o investimento na educação. Sobre essa questão, Motta e Frigotto (2017, pp. 366-367) apontam que:

A PEC n- 55, aprovada no Congresso Nacional, representa, sem dúvida, as
forças sociais que golpearam a democracia brasileira e constitui-se na maior
agressão às conquistas de direitos da classe trabalhadora desde o fim da es-
cravidão. Liquida o Estado brasileiro como agente de garantia de direitos uni-
versais, dos quais se destacam o trabalho, a educação, a saúde e a habitação.
[...] O caráter desumano e criminoso da PEC no 55 é que, ao congelar por 20
anos o investimento público na área social, reserva toda a riqueza produzida 
para ganhos do capital, em especial mediante juros criminosos acobertados por leis injustas. Leis e Justiça têm caminhado em sentido oposto aos interesses da classe trabalhadora e de forma aberta (MOTTA; FRIGOTTO, 2017, pp. 366-367).

Um dos principais problemas da implementação dessa Ementa para EJA é o esvaziamento político das metas do PNE, cujo objetivo é acabar com o analfabetismo absoluto e reduzir em 50\% o analfabetismo funcional até 2024 (meta 9); Essa ementa inviabiliza também a meta 3, que aponta a universalização do atendimento escolar para a população de 15 a 17 anos até 2016 (PNE, 2014). Dados do Instituto Brasileiro de Geografia e Estatística [IBGE] (2018b) indicam que nenhuma grande região brasileira tinha alcançado a meta até 2018, deduzse com isso que é muito provável que não seja atingida até o final do prazo. Esses entraves perpassam as questões educacionais e os múltiplos conflitos inerentes a esse contexto.

Além da redução dos recursos financeiros, que atinge diretamente a modalidade, no ano de 2019, a EJA sofreu outros ataques. O Decreto n. 9.465/19 extinguiu a Secretaria de Educação Continuada, Alfabetização, Diversidade e Inclusão (Secadi), onde alocava a Diretoria de Políticas de EJA. No momento presente não há nenhuma secretaria responsável pela modalidade, por conseguinte, nenhum projeto ou proposta governamental direcionados a esse público. Além disso, o Programa Nacional do Livro Didático de EJA deixou de existir, afetando drasticamente os alunos, já que, em muitas escolas, é o único recurso pedagógico disponível em sala de aula.

Políticas como essas, dificultam o acesso à escola e levam milhões de sujeitos a não terem a oportunidade de serem reconhecidos como cidadãos detentores de direitos plenos na sociedade. Pelos dados da Síntese de indicadores sociais (IBGE, 2018c), que analisa a condição de vida da população brasileira, permite-se constatar que o sujeito da EJA é marcado pelas desigualdades estruturais, sobretudo aquelas evidenciadas pelo desemprego e a informalidade incidentes nos grupos populacionais considerados mais vulneráveis - pretos ou pardos, mulheres e jovens -, bem como pela subutilização da força de trabalho.

O índice de analfabetismo da população de 15 anos ou mais no Brasil passa de 6,8\%, ou seja, cerca de 11 milhões de brasileiros não sabem ler e escrever um bilhete simples (IBGE, 2018b). Essa condição se manifesta numa baixa qualidade de vida, pois a falta de escolaridade básica gera uma série de 
privações concretas e simbólicas, que se manifestam nas exigências do trabaIho, nas práticas sociais cotidianas e até nas relações interpessoais.

Diante ao exposto até aqui, apesar dos avanços na legislação, pode-se destacar que um dos grandes desafios da EJA na atualidade é produzir um ensino numa perspectiva crítica e emancipatória, de forma que o jovem e o adulto consigam transformar a realidade excludente e produtora de desigualdades sociais.

\section{PROGRAMA DE EDUCAÇÃO DE JOVENS E ADULTOS (PEJA): BREVE HIS- TÓRICO E CONJUNTURA ATUAL}

Os primeiros passos para tentar reduzir o grande contingente de jovens analfabetos no município do Rio de Janeiro foram dados em 1984, com a implementação de três escolas de um projeto-piloto, que atendia aos jovens de 14 a 20 anos das classes populares, egressos do ensino regular (RIO DE JANEIRO, 2017). Em 1985, a EJA foi ampliada e passou a ofertar a alfabetização no Projeto de Educação Juvenil (PEJ), nos Centros Integrados de Educação Pública, popularmente conhecidos como CIEPS, que surgiu na gestão de Leonel Brizola, sob coordenação de Darcy Ribeiro, no Estado do Rio de Janeiro (FÁVERO; ANDRADE; BRENNER, 2007).

No decorrer dos anos, após diversas reformulações, foi também implementado e segundo segmento do Ensino Fundamental (PEJ II). Apesar das ampliações dos projetos iniciais de alfabetização, por mais uma década o ensino era vinculado aos programas sociais, ou seja, voltados a reinserção social, não emitia certificação ou qualquer outra espécie de documentação oficial. Somente em março de 1999, o Conselho Municipal de Educação aprovou o Projeto de Educação Juvenil, nas suas etapas PEJ I e PEJ II, através do Parecer 03/99, que garantia o direito a documentação de terminalidade, retroativa a 1998, a todos os jovens e adultos que frequentaram a modalidade de ensino (FÁVERO et al., 2007).

Apesar dos avanços da legislação nacional no que concerne ao ensino de jovens e adultos, como já comentados neste artigo, (Lei n. 9.394/96, Resolução CNE/CEB n. 1/2000, Parecer CNE/CEB 11/2000, Lei n. 10.172/2001), o Programa de Educação de Jovens e Adultos (PEJA) foi implementado como política 
pública municipal do Rio de Janeiro somente em 2005, pelo Parecer 06/2005 e ainda permanece em vigor nos dias atuais. Além de alterar a designação vigente na época, de PEJ para PEJA, o documento previa ações como ampliação da oferta de vagas, oferecimento da modalidade no horário diurno, estabelecimento de parcerias com a sociedade civil, reconhecimento do Centro Municipal de Referência de Educação de Jovens e Adultos (CREJA e CEJA) (RIO DE JANEIRO, 2017).

O projeto apresentou uma proposta mais abrangente de EJA, pois levava em conta a aprendizagem fora do espaço escolar, como a realização de fóruns de debate de alunos (Encontro Anual de Alunos) e apresentação de exposição anual de trabalhos do PEJA (EXPOPEJA), também previa investimento na formação do professor da modalidade, com curso de formação continuada e realização de Centros de Estudo semanais. Além disso, apresentava importantes ações no campo do currículo, tornando-se uma referência para a EJA nacional. A proposta curricular do PEJA apresenta duas etapas (PEJA I e PEJA II), estruturadas em blocos de aprendizagem e não em séries, de modo a adequar o ensino ao ritmo de aprendizado dos alunos, ou seja, não é necessário que o aluno curse um ano letivo para mudar de bloco.

A PEJA I, etapa referente aos anos iniciais do Ensino Fundamental, dura em média dois anos letivos, possuindo 400 horas de carga horária anual, distribuídas em dois blocos. No primeiro bloco, o aluno vivencia o processo inicial de alfabetização, compreendido como aquisição da base alfabética da escrita, numa visão de leitura que considera a relação texto-contexto, com mediação direta do professor; já no bloco 2, a vinculação texto-contexto é intensificada, a partir da abordagem interdisciplinar das diferentes áreas do conhecimento (RIO DE JANEIRO, 2017).

O PEJA II, etapa referente aos anos finais do Ensino Fundamental, é estruturada, também, em dois blocos de aprendizagem, com duração de 801 horas anuais. Cada bloco incorpora três unidades de progressão, sendo que 134 horas são de atividades curriculares de interatividade direta professor-aluno, realizadas na sala de aula, e 133 horas de atividades curriculares de interatividade indireta, realizadas fora da sala de aula. As atividades presenciais de interação direta professor-aluno, são realizadas em salas ambientes, específicas para cada componente curricular (Língua Portuguesa, Matemática, História e Geografia, 
Ciências, Linguagens Artísticas (somente para EJA II Bloco 1) e Língua Estrangeira (somente para EJA II Bloco 2) (RIO DE JANEIRO, 2017).

Consoante dados do Censo 2019, há 27.885 alunos matriculados no PEJA no município do Rio. A SME garante a modalidade de ensino em 137 escolas, distribuídas nas 11 Coordenadorias Regionais de Educação, e em mais 3 escolas exclusivas, nas formas semipresencial e Educação a Distância (EAD). Embora haja mais oferta no horário noturno, também há escolas que oferecem no horário diurno, respeitando a especificidade do público da EJA nas suas diferentes necessidades. ${ }^{3}$

Não há como negar que a proposta curricular do PEJA apresenta boas ações para implementar uma política de atendimento a jovens e adultos trabaIhadores com escolarização incompleta ou precária. No entanto, a realidade do município não é muito diferente da EJA de outras partes do país. Em conformidade com Lemos (2017) a modalidade no município apresenta acentuada evasão escolar, descontinuidade das políticas de formação dos docentes, falta de investimento em estrutura específica e material pedagógico para o aluno do PEJA e alto índice de alunos transferidos do ensino regular após sucessivas reprovações e grande defasagem idade/série quando completam 15 anos. A esse respeito, Fávero et al. (2017) comenta que:

\begin{abstract}
A procura do Programa por jovens é crescente, pela "expulsão" da escola regular, ocasionada pelo mal justificado "fracasso escolar". Há os alunos que são "convidados" pelos coordenadores dos turnos diurnos a se transferirem para o PEJA, para deixar de "causar problemas". Por outra parte, essa procura é justificada pela entrada do jovem no mundo do trabalho; gravidez precoce, situações decorrentes da violência etc., que motivaram a interrupção dos estudos (FÁVERO et al., 2007, p. 11).
\end{abstract}

Apesar desses jovens estarem na faixa etária permitida para matrícula na EJA, a integração na turma não é tão simples, pois além da inadequação dos conteúdos e a falta de identificação desse jovem com a escola, há também diferença de postura e de ritmos de aprendizagem com relação aos colegas mais velhos, acarretando exclusão e, consequentemente, evasão escolar.

Decerto que o PEJA apresenta boa estrutura curricular para a aprendizagem de jovens e adultos, mas para que seja considerado referência nacional e que proporcione uma educação diferenciada de verdade, é preciso viabilizar as

\footnotetext{
${ }^{3}$ Dados coletados do site da prefeitura do Rio de Janeiro, no dia 18 de junho, de 2020. Disponível em: (http://www.rio.rj.gov.br/web/sme/educacao-em-numeros, recuperado em 26 de março, 2019)
} 
propostas na prática, atingindo o maior número de alunos em condição de desigualdade social.

\section{ENSINO REMOTO X EAD: REFLEXÃO ACERCA DO USO DAS TECNOLO- GIAS DA INFORMAÇÃO E COMUNICAÇÃO NA EDUCAÇÃO DE JOVENS E ADULTOS}

De forma aligeirada e sem tempo hábil para refletir sobre os impactos e prejuízos que a suspensão das aulas, devido as medidas de confinamento e distanciamento social, ocasionariam na educação, as instituições de ensino federal, estaduais, municipais e distrital implementaram ações, excepcionalmente através do Ensino Remoto, de forma a dar continuidade ao processo ensino aprendizagem.

O Ensino Remoto (EAR), também conhecido como Estratégias de Aprendizagem Remota, é exclusivamente um plano emergencial, tem como finalidade adaptar as aulas presenciais aos mecanismos de contato remoto disponíveis, diante da excepcionalidade da conjuntura específica do distanciamento social. A Educação a Distância (EAD), por sua vez, é um processo de ensino-aprendizagem, mediado por tecnologias, em que ocorre uma separação espacial e/ou temporalmente entre professores e alunos (MORAN, 2002).

Como as discussões sobre a EAD já estão consolidadas no Brasil, há legislação específica que a regulamenta. O artigo 80 da LDB 9394/96 destaca que o poder público incentivará o desenvolvimento de ensino a distância em todos os níveis e modalidades de ensino. O Decreto 2.494/98, em seu artigo 1, especifica que a EAD possibilita a autoaprendizagem, com a mediação de recursos didáticos sistematicamente organizados, apresentados em diferentes suportes de informação, utilizados isoladamente ou combinados, e veiculados pelos diversos meios de comunicação. Isso significa que nessa modalidade, o professor atua como tutor, não há, necessariamente interação entre professor e aluno; o conteúdo é replicado de forma a atender o maior número possível de alunos.

O Conselho Nacional de Educação (CNE) aprovou no dia 28 de abril deste ano o Parecer CNE/CP05/2020 que orienta, em nível nacional, a respeito da reorganização do calendário escolar e da possibilidade de cômputo de atividades 
Out.-Nov. 2021
v.1, n.9, 03-24
ISSN: $2676-0428$

não presenciais para fins de cumprimento da carga horária mínima de 800 horas por ano.

De acordo com o parecer, é possível usar diversas estratégias de aprendizagem através da metodologia remota: transmissão de aulas e conteúdos educacionais via televisão ou rádio; aulas ao vivo e online, ou videoaulas gravadas, transmitidas por redes sociais; disponibilização de plataformas de envio de conteúdos digitais on-line e até mesmo envio de material impresso. O documento aponta que a comunicação é essencial neste processo, assim como a elaboração de guias de orientação das rotinas de atividades educacionais não presenciais para orientar famílias e estudantes, sob a supervisão de professores e dirigentes escolares (PARECER CNE/CP05/2020).

Embora fosse necessária uma proposta oficial do Ministério da Educação que direcionasse as instituições de ensino de todo o país no que diz respeito às medidas de reorganização do calendário escolar, o Parecer CNE/CP05/2020 deixa muito a desejar e está longe de garantir o direito a uma educação pública, gratuita e inclusiva, como prevê a Constituição Federal de 1988. Num momento de emergência pública, como estamos vivendo, as medidas apontadas não consideram questões como as desigualdades de acesso a serviços básicos e as disparidades sociais, educacionais e regionais que atingem o cotidiano de estudantes e de suas famílias.

Muito se debate no meio educacional sobre a importância do uso da tecnologia para facilitar a aprendizagem e contribuir para mobilizar as competências desejadas, sejam intelectuais, emocionais, pessoais e comunicacionais (Moran, 2007). No entanto, a realidade das escolas públicas brasileiras está muito longe de usufruir dos benefícios promovidos pela tecnologia no contexto educacional. Ademais, a forma como as secretarias de educação inseriram a inclusão do Ensino Remoto nas escolas, durante o período de distanciamento social, ignorou diversos fatores, principalmente os socioeconômicos.

Quando se reflete sobre o uso das Tecnologias da informação e comunicação (TDIC) na EJA, a situação se mostra ainda mais precária e distante da

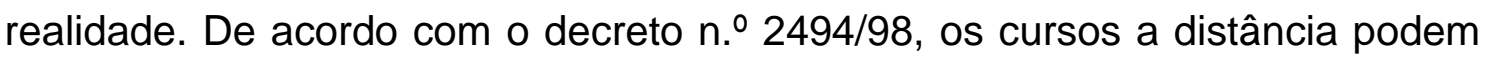
conferir certificação ou diploma de conclusão do ensino fundamental para jovens e adultos. No entanto, o ensino presencial já traz grandes desafios difíceis de serem superados, como a falta de recursos e investimentos, capacitação

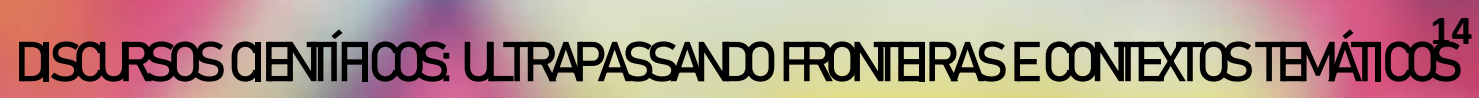


adequada de profissionais para trabalhar com a modalidade, falta de recursos e materiais didáticos.

Os dados revelados pela pesquisa Nacional por Amostra de Domicílios Contínua - Tecnologia da Informação e Comunicação (IBGE, 2018a) apontaram que 46 milhões de brasileiros não têm acesso à internet. Referente aos estudantes, 45,2\% não utilizaram internet em 2018, por motivos de ordem econômica, como falta de recursos para pagar serviços de acesso à internet e compra de aparelhos eletrônicos apropriados.

Esses dados, junto com o índice de 6,8\% de brasileiros analfabetos (IBGE, 2018b), revelam que um ensino exclusivamente a distância, seja EAR ou $E A D$, ignora a situação precária e desigual em que vivem milhões de estudantes e, consequentemente, contribui de forma significativa com o aumento da exclusão social do aluno da EJA.

Não há como negar que a TDIC pode oportunizar ao indivíduo a inclusão educacional e a inclusão tecnológica, inserindo o sujeito de forma mais igualitária na sociedade contemporânea. Contudo, é necessário pensar políticas púbicas preocupadas com a erradicação do "analfabetismo digital" (SANTOS et al., 2012) e melhorias da condição de vida do jovem trabalhador, só assim para continuar acreditando na universalização do ensino público.

\section{ENSINO REMOTO NO PEJA DO SISTEMA MUNICIPAL DE ENSINO DO RIO DE JANEIRO}

Diante ao cenário atual de distanciamento social, a SME implementou diversas ações ${ }^{4}$, com a finalidade de minimizar os impactos da pandemia do Coronavírus no ensino dos alunos das escolas públicas. Entre as medidas adotadas, estão a suspensão das aulas presenciais; disponibilidade de material pedagógico para alunos, através de redes sociais, como Facebook e WhatsApp; criação de plataforma de aulas digitais e aplicativo com aulas específicas, divididas por segmento, da pré-escola ao ensino de jovens e adultos.

Para refletir sobre o impacto do EAR no PEJA, será analisado o dossiê elaborado pelo Fórum de educação de Jovens e Adultos do estado do Rio de

4 Dados coletados do site da Prefeitura do Rio de Janeiro, no dia 06 de junho, de 2020. Disponível em (http:/prefeitura.rio/educação/, recuperado em 26 de maio, 2019) 
Janeiro, Fórum EJA-RJ5 ${ }^{5}$ espaço de mobilização nacional, que surgiu em 1994, que congrega os diversos segmentos da EJA, para discutir as políticas públicas voltadas para essa modalidade de ensino, e os dados de um estudo de caso com professores da escola municipal Tatiana Chagas Memória, localizada no subbairro Jardim Maravilha, Guaratiba, na Zona Oeste da cidade do Rio de Janeiro. Objetiva-se com isso, vislumbrar se as condições de acesso ao EAR oferecido pela prefeitura, diante à crise instaurada pela pandemia, está atingindo a todos os públicos, inclusive em áreas com maior vulnerabilidade social.

De acordo com os dados do Índice de desenvolvimento Social (IDS) ${ }^{6}$ que comparou as realidades microurbanas da cidade do Rio de Janeiro, o bairro de Guaratiba está em último lugar, em comparação ao IDS das 32 Regiões Administrativas do município. Além disso, essa região é marcada pela desigualdade social e possui características marcadamente rurais, com falta de infraestrutura básica e outros recursos essenciais para uma boa qualidade de vida (CAVALLIERI; LOPES, 2008).

A instituição escolar oferece somente o PEJA II, há apenas uma turma de cada etapa, no horário da manhã, e possui 140 alunos matriculados, com idades entre 13 e 34 anos. Do quantitativo total de alunos do PEJA, aproximadamente $90 \%$ dos alunos têm menos de 20 anos, oriundos do ensino regular da própria escola. Como estrutura, a escola possui quadra de esporte coberta, biblioteca, laboratório de informática (localizada na sala da biblioteca, porém não está ativo, pois os equipamentos não funcionam adequadamente). No que diz respeito à internet, a escola disponibiliza acesso aos alunos no pátio da escola, porém a qualidade do serviço é ruim, pois o bairro não apresenta provedores de banda larga de internet com alta conexão, o que inviabiliza, inclusive, a utilização em atividades pedagógicas em salas de aula.

\section{FÓRUM EJA-RJ: PESQUISA COM PROFESSORES DA REDE MUNICIPAL DE ENSINO}

Com vistas a estabelecer uma interlocução com os sujeitos mais diretamente envolvidos nesse processo, o Fórum EJA-RJ promoveu uma consulta 
pública, através de questionário on-line, com 147 professores/as do PEJA, entre os dias 23 de abril e 3 de maio de 2020. Nessa pesquisa, foi utilizado um questionário, com três blocos de perguntas: 1. Dados gerais dos entrevistados; 2. Interatividade dos professores com os educandos; 3 . Terminalidade dos alunos que estão na última etapa. Para a presente pesquisa, vamos apresentar e analisar especificamente a parte dois do questionário, que apresenta cinco questões. As perguntas desse bloco estão relacionadas a todas as etapas do PEJA e exibem dados relativos à interação dos envolvidos no processo de ensino/aprendizagem, como alunos, professores e a escola.

Nas duas primeiras perguntas, os professores foram indagados se, durante a pandemia, os alunos mantiveram contatos com os professores e/ou a escola e qual o meio mais utilizados por eles. Na primeira questão, $81,6 \%$ dos professores disseram que os alunos mantiveram algum contato com os professores/escola, 9,5\% responderam que não e 8,8\% não souberam responder. Em referência ao meio mais utilizado, os docentes poderiam optar por mais de uma resposta, segue tabela de dados.

Tabela 1. Pergunta 2 - Qual o meio mais utilizado pelos alunos para entrar em contato com a escola/professores?

\begin{tabular}{l|l|l}
\hline OPÇÕES & RESPOSTAS & $\begin{array}{l}\text { PERCENTUAL } \\
(\%)\end{array}$ \\
\hline WhatsApp pessoal do professor & 69 & 46,9 \\
\hline Grupo de WhatsApp da turma & 78 & 53,1 \\
\hline Grupo de WhatsApp da escola & 15 & 10,2 \\
\hline Grupo ou página do Facebook da escola & 91 & 61,9 \\
\hline E-mail institucional da escola & 8 & 5,4 \\
\hline Outro & 23 & 16,1 \\
\hline
\end{tabular}

Fonte: Elaborado para este estudo.

Os dados da tabela indicam que as redes sociais foram os meios mais utilizados pelos alunos para contactarem a escola ou o professor. O Facebook da escola foi a forma mais usada pelos alunos, com $61,9 \%$, seguido pelo grupo de WhatsApp da turma, com $53,1 \%$, e WhatsApp pessoal do professor, com $46,9 \%$; somente $5,4 \%$ dos alunos contactaram a escola através do E-mail institucional.

A terceira pergunta feita aos docentes foi se os alunos realizaram as atividades remotas propostas pela SME, sendo possível responder mais de uma 
opção; em seguida, na quarta pergunta, o questionário indagou se as escolas estavam propondo atividades remotas. Segundo a pesquisa, $84,4 \%$ das escolas ofereceram atividades remotas para os alunos. No que se refere à terceira pergunta, segue tabela baixo:

Tabela 2. Pergunta 3 - Os alunos realizaram as atividades remotas?

\begin{tabular}{l|l|l}
\hline OPÇÕES & $\begin{array}{l}\text { RESPOS- } \\
\text { TAS }\end{array}$ & $\begin{array}{l}\text { PERCENTUAL } \\
(\%)\end{array}$ \\
\hline $\begin{array}{l}\text { Sim, a maioria dos alunos está realizando as } \\
\text { atividades }\end{array}$ & 18 & 12,2 \\
\hline $\begin{array}{l}\text { Parcialmente, pois apenas uma pequena } \\
\text { parte está realizando as atividades }\end{array}$ & 69 & 46,9 \\
\hline $\begin{array}{l}\text { Não, os alunos não estão realizando as ati- } \\
\text { vidades }\end{array}$ & 22 & 15 \\
\hline Não sei informar & 29 & 19,7 \\
\hline Outro & 10 & 6,2 \\
\hline
\end{tabular}

Fonte: Elaborado para este estudo.

Como é possível perceber, apenas $12,2 \%$ dos entrevistados responderam que a maioria dos alunos está realizando as atividades. A grande parte respondeu que os alunos realizaram parcialmente as atividades, com 46,9\%, ou que não estão realizando nenhuma atividade, com 15\%. Esses dados revelam mais claramente que mais de $60 \%$ dos alunos não tiveram uma aprendizagem efetiva através das ações remotas implementadas pela SME.

Na quinta e última pergunta, os professores responderam qual o meio que os educandos estão acessando para realizar as atividades remotas, podendo responder a mais de uma opção. Seguem as respostas:

Tabela 3. Pergunta 5 - Qual o meio usado pelos educandos para acessar as atividades remotas?

\begin{tabular}{l|l|l}
\hline OPÇÕES & $\begin{array}{l}\text { RESPOS- } \\
\text { TAS }\end{array}$ & PERCENTUAL (\%) \\
\hline WhatsApp pessoal do professor & 46 & 31,3 \\
\hline Grupo de WhatsApp da turma & 72 & 49 \\
\hline Grupo de WhatsApp da escola & 17 & 11,6 \\
\hline Grupo ou página do Facebook da escola & 90 & 61,2 \\
\hline E-mail institucional da escola & 4 & 2,7 \\
\hline Outro & 35 & 24,4 \\
\hline
\end{tabular}

Fonte: Elaborado para este estudo. 
O Facebook da escola foi o meio mais acessado pelos alunos para realizar as atividades, com $61,2 \%$, seguido pelo WhatsApp pessoal do professor, com $31,3 \%$; apenas $11,6 \%$ dos alunos usaram o grupo de WhatsApp da turma, para acessar os conteúdos remotos.

\section{PESQUISA DE CAMPO COM PROFESSORES DE UMA ESCOLA DA PERI- FERIA DA CIDADE DO RIO DE JANEIRO}

A escola pesquisada possui apenas quatro docentes de PEJA (disciplinas de Língua Portuguesa, Ciências, História/Geografia e Matemática) para atender a demanda do bairro. Os professores responderam a um questionário online, produzido pela pesquisadora, semelhante ao proposto pelo Fórum EJA-RJ, com quatro blocos de perguntas: 1. Dados gerais dos entrevistados; 2 . Interatividade dos professores com os educandos; 3 . Relação do docente com as ações remotas da prefeitura 4. Avaliação do docente no tocante ao EAR. As escolhas dessas perguntas foram elaboradas com a intenção de verificar se está havendo interação entre professores e alunos dessa escola, através das ações implementadas pela prefeitura.

O bloco 2 apresenta cinco questões: se os alunos mantiveram contato com a escola; se os professores mantiveram contato com os alunos; quais os meios utilizados pelos alunos que interagiram; se o professor propôs atividade remota; se os alunos realizaram as atividades remotas;

Os docentes relataram que a escola possui meios de contato com os alunos, como grupo de WhatsApp, página de Facebook e E-mail institucional, porém poucos alunos contactaram diretamente a escola para saber das atividades. Todos os docentes mencionaram viabilizar atividades via Facebook e $50 \%$ utilizaram também a plataforma digital. Nenhum dos docentes teve retorno dos alunos referente às atividades propostas. Além disso, não souberam responder se os alunos conseguiram ter acesso às atividades, já que $100 \%$ dos professores expuseram não ter tido nenhum contato com os alunos.

O bloco 3 se referia à relação do docente com as ações remotas da prefeitura. O questionário apresentou quatro perguntas: se a SME ofereceu algum curso de capacitação para a realização do EAR; se o professor precisou comprar ou adquirir computadores, acessórios e dados de internet para possibilitar esse 
acesso; se o docente teve acesso a plataforma e se teve facilidade de acessar a plataforma.

Segundo os professores, a SME ofereceu um curso de ferramentas digitais para trabalho remoto e disponibilizou canais para suprir dúvidas. $75 \%$ dos docentes declararam ter realizado o curso. Quanto à plataforma, todos tiveram acesso, porém 50\% tiveram dificuldade em lidar com a ferramenta digital. Além disso, a metade dos docentes entrevistados precisou comprar ou adquirir computadores, acessórios e dados de internet para possibilitar esse acesso.

No bloco 4, os docentes deveriam avaliar o EAR, indicando os pontos positivos e negativos. Como ponto positivo das ações implementadas pela SME, os docentes apontarem a possibilidade de os alunos continuarem a ter acesso aos conteúdos escolares, mantendo o vínculo com a escola. Como a avaliação negativa do ensino virtual, os docentes destacaram a exclusão dos alunos do PEJA, por falta de recursos adequados e disponíveis para acessar o material pedagógico. Conforme declaração de uma das docentes, a maioria dos alunos, que acessam a internet, utiliza celular pré-pago, com poucos dados móveis, o que inviabiliza realizar as tarefas disponíveis na página do Facebook e/ou plataforma digital. Outro docente relatou também que muitos alunos não conseguem realizar as atividades sem a mediação do professor, devido às dificuldades na leitura e na escrita, o que dificultaria o processo de ensino aprendizagem autônomo.

\section{RESULTADOS}

Os resultados das duas pesquisas vão ao encontro da tese defendida neste artigo, que o EAR contribui para a exclusão social e digital dos alunos do PEJA. Os dados apontam que mais de $60 \%$ dos alunos não tiveram uma aprendizagem efetiva através das ações remotas implementadas pela SME. Tampouco foi possível avaliar se os alunos estão realizando as atividades propostas, nem os que indicaram acessar o material, uma vez que não há um retorno das atividades dos alunos pelos meios disponibilizados oficialmente pela prefeitura.

No que diz respeito ao contato dos alunos com a escola e professores, $81,6 \%$ dos professores entrevistados pelo Fórum EJA-RJ disseram que os alunos mantiveram algum contato. No entanto, os professores da escola Tatiana 
Memória tiveram pouco ou nenhum contato com os alunos. Sobre essa diferença, vale destacar a grande diversidade das regiões do município do Rio de Janeiro. Bairros situados na Zona Oeste da cidade têm grande contingente de alunos em situação de vulnerabilidade social (CAVALLIERE; LOPES, 2008). Além disso, o acesso à internet é precário nessa região, inclusive a escola pesquisada não possui internet de alta conexão, por inviabilidade técnica. Esses dados corroboram para indicar a exclusão dos alunos do PEJA dessa localidade, já que grande parte dos alunos não tem condições técnicas para acessar as atividades remotas.

Embora o número de entrevistados seja pequeno em vista da quantidade de docentes que atuam no PEJA, foi possível perceber, tanto pelo dossiê do Fórum EJA-RJ quanto pelo estudo de caso, as dificuldades enfrentadas pelos professores e pelos alunos para acessar o EAR, essa realidade deixa evidente a falta de igualdade de acesso a um ensino de qualidade.

\section{CONSIDERAÇÕES FINAIS}

Levar em conta a opinião dos professores do PEJA é de suma importância para identificar a realidade do ensino nas escolas do município do Rio de Janeiro e traçar políticas públicas mais eficientes, mesmo em tempos de pandemia.

A opinião dos professores consultados reforça a tese desse artigo de que o Ensino Remoto é pouco eficiente para o público da EJA, uma vez não leva em conta as especificidades desse grupo, como alto índice de alunos com distorção idade/ano de escolaridade, com graves deficiências no processo ensino-aprendizagem; falta de recursos para aquisição de equipamentos com acesso à internet, que suporte o material disponível nas redes sociais e/ou plataformas digitais.

$A$ inclusão digital na EJA, não significa instaurar um sistema $E A D$, como muitos governantes vêm tentando fazer nas escolas públicas do país. Significa, antes de tudo, repensar a escola presencial e os recursos destinados a esse público, de forma a ampliar o acesso às tecnologias da comunicação e da informação. Munir os professores de ferramentas digitais nos espaços escolares, em tempos de regularidade social, pode trazer significativas mudanças no processo de ensino aprendizagem, ampliando dessa forma, a inclusão social e digital desses jovens. 
Ademais, é preciso que as políticas públicas possam garantir na prática ações mais adequadas para a erradicar o analfabetismo e produzir educação básica de qualidade. Para isso, é imprescindível aumentar o financiamento destinado à EJA, investir na formação do profissional que atua na modalidade, assegurando a qualificação e valorização profissional.

\section{REFERÊNCIAS BIBLIOGRÁFICAS}

BRASIL. Decreto n. 2494/98, de 10 de fevereiro de 1998. Regulamenta o art. 80 da Lei no 9.394, de 20 de dezembro de 1996, e dá outras providências Brasília: Diário Oficial [da] União. Disponível em: http://www4.planalto.gov.br/legislacao/. Acessado em mar., 2020.

. Lei no 9.394, de 20 de dezembro de 1996. Estabelece as diretrizes e bases da educação nacional, Brasília: Diário Oficial [da] União. Disponível em: http://www4.planalto.gov.br/legislacao/. Acessado jan., 2020.

. Decreto n. 9465/19, de 02 de janeiro de 2019. Aprova a Estrutura Regimental e o Quadro Demonstrativo dos Cargos em Comissão e das Funções de Confiança do Ministério da Educação. Brasília: Diário Oficial [da] União. Disponível em: http://www4.planalto.gov.br/legislacao/. Acessado em dez., 2020.

. Emenda Constitucional no 95, de 15 de dezembro de 2016. Altera o Ato das Disposições Constitucionais Transitórias, para instituir o Novo Regime Fiscal, e dá outras providências, Brasília: Diário Oficial [da] União. Disponível em: http://www4.planalto.gov.br/legislacao/. Acessado em jan., 2020.

. Parecer CEB11/2000 - Diretrizes curriculares nacionais para a educação de jovens e adultos. Brasília: Diário Oficial [da] União. Disponível em: http://www4.planalto.gov.br/legislacao/. Acessado em jan., 2020.

. Parecer CNE/CP nำ5/2020, de 28 de abril de 2020 - Reorganização do Calendário Escolar e da possibilidade de cômputo de atividades não presenciais para fins de cumprimento da carga horária mínima anual, em razão da Pandemia da COVID-19. Brasília: Diário Oficial [da] União. Disponível em: http://www4.planalto.gov.br/legislacao/. Acessado em abr., 2020.

Plano Nacional de Educação 2001-2010. In Lei n. 10.172, de 09 de janeiro de 2001, Aprova o Plano Nacional de Educação (PNE) e dá outras providências. Brasília: Diário Oficial [da] União. Disponível em: http://www4.planalto.gov.br/legislacao/. Acessado em jan., 2020.

Plano Nacional de Educação 2014-2024. In Lei no 13.005, de 25 de junho de 2014, Aprova o Plano Nacional de Educação (PNE) e dá outras providências. Brasília: Diário Oficial [da] União. Disponível em: http://www4.planalto.gov.br/legislacao/. Acessado em jan., 2020. 
. Resolução CNE/CEB № 1, de 5 de julho de 2000. Diretrizes curriculares nacionais para a educação de jovens e adultos. Brasília: Diário Oficial [da] União. Disponível em: http://www4.planalto.gov.br/legislacao/. Acessado em jan., 2020.

CAVALLIERE, F.; LOPES, G.P. Índice de Desenvolvimento Social - IDS: Comparando as realidades microurbanas da Cidade do Rio de Janeiro. Rio de Janeiro: Instituto Municipal de Urbanismo Pereira Passos da Prefeitura do Rio de Janeiro, 2008.

FÁVERO, O.; ANDRADE, E.R.; BRENNER, A.K. Programa de Educação de Jovens e Adultos (PEJA). In: HADDAD, Sérgio. Novos caminhos em Educação de Jovens e Adultos - EJA. São Paulo: Global, 2007.

FREIRE, P. Pedagogia do Oprimido. (42..$^{\text {a }}$ ed.). Rio de Janeiro: Paz e Terra, 2005.

2009.

. Educação como prática da liberdade. Rio de Janeiro: Paz e Terra,

GADOTTI, M.; ABRÃO, P. (Org.). Paulo Freire, anistiado político brasileiro. São Paulo: Editora e Livraria Instituto Paulo Freire, 2012.

IBGE. Instituto Brasileiro de Geografia e Estatística. Pesquisa Nacional por Amostra de Domicílios Contínua (PNAD Contínua). Brasil: Instituto Brasileiro de Geografia e Estatística, 2018a. Disponível em: https://www.ibge.gov.br/. Acessado em fev., 2020.

Diretoria de Pesquisas, Coordenação de Trabalho e Rendimento, Pesquisa Nacional por Amostra de Domicílios Contínua 2017-2018. Brasil: Instituto Brasileiro de Geografia e Estatística, 2018b. Disponível em: https://www.ibge.gov.br/. Acessado em mar. 2020.

Síntese de Indicadores Sociais: Uma análise das condições de vida da população brasileira 2018. Brasil: Instituto Brasileiro de Geografia e Estatística, 2018c. Disponível em: https://www.ibge.gov.br/. Acessado em mar., 2020.

INEP. Instituto Nacional de Estudos e Pesquisas Educacionais Anísio Teixeira (Inep). Censo Escolar da Educação Básica 2018: notas estatísticas. Brasília: INEP

HADDAD, S. Dossiê - Paulo Freire. O Legado Global. Política, Educação, Educação e Atualidade do Pensamento Freiriano, 27. mai. 2019. (e214048), 35. https://doi.org/10.1590/0102-4698214048

A educação continuada e as políticas públicas no Brasil. p. 27-38. In: Revista Brasileira de Educação. v. 1, n. 0. Rio de Janeiro: ANPED, 2007.

LEMOS, A. G. de. Despeja na EJA: reflexões acerca da migração perversa de jovens para o peja no município do Rio de janeiro (Dissertação de Mestrado). Universidade Federal do Estado do Rio de Janeiro, Rio de Janeiro, Brasil, 2017. Recuperado 1 de fevereiro de 2020. 
MACHADO, M. M. A educação de jovens e adultos Após 20 vinte anos da Lei no 9.394, de 1996. 20 anos de LDB, v. 10, n. 19, p. 429-45, 2017. https://doi.org/10.22420/rde.v10i19.687.

MORAN, J. M. O que é Educação a Distância? Informe de CEAD - Centro de Educação a Distância, ano 1, n. 5, p. 1-3, Out. 1994, atualizado em 2002. Rio de Janeiro: SENAI, 2002. Disponível em: http://www2.eca.usp.br/moran/wp-content/uploads/2013/12/dist.pdf. Acesso em: 10 de jun. 2020.

A educação que desejamos: novos desafios e como chegar lá. Campinas: Editora Papirus Editora, 2003.

MOTTA, V.C.; FRIGOTTO, G. Por que a urgência da reforma do Ensino Médio. Campinas: Revista Educação e Sociedade, n. 38. p. 355-72, 2017. https://doi.org/10.1590/es0101-73302017176606

RIO DE JANEIRO. Prefeitura do Rio de Janeiro. Documentos norteadores do PEJA. Rio de Janeiro: Equipe da Gerência de Educação de Jovens e Adultos, 2017. Disponível em: http://antigo.rioeduca.net/rioeduca/BLOG\%20PROFESSORES/PEJA/Documentos\%20Norteadores\%20\%20do\%20PEJA\%202017.pdf. Acessado em fev., 2020.

SANTOS, J. D. A; ROSA, A. C.; MELO, A. K. D. O Uso Das Tecnologias Na Educação de Jovens e Adultos: Reflexões Sobre Um Relato De Experiência. In Infoinclusão: possibilidades de ensinar e aprender, 3ํㅗำósio de Educação e Comunicação - Edição Internacional. Sergipe: Interfaces Científicas - Educação /UNIT, 2012. 